\title{
Efficacy of Selected Agroindustrial Wastes in Managing Root-Knot Nematodes on Black Nightshade in Kenya
}

\author{
Shem Bonuke Nchore, ${ }^{1}$ J. W. Waceke, ${ }^{2}$ and G. M. Kariuki1 \\ ${ }^{1}$ Plant and Microbial Sciences Department, Kenyatta University, Nairobi, Kenya \\ ${ }^{2}$ Department of Agricultural Sciences and Technology, Kenyatta University, Nairobi 00100, Kenya \\ Correspondence should be addressed to Shem Bonuke Nchore, nchoree@gmail.com
}

Received 29 April 2012; Accepted 31 July 2012

Academic Editors: R. Burt and T. E. Fenton

Copyright ( 92012 Shem Bonuke Nchore et al. This is an open access article distributed under the Creative Commons Attribution License, which permits unrestricted use, distribution, and reproduction in any medium, provided the original work is properly cited.

\begin{abstract}
Black nightshade is commercially cultivated in Kenya as a source of nutrition and income to the rural populations. Besides insect pests, root-knot nematodes (RKN) are important production constraints of this vegetable. Little information is available on the efficacy of Tithonia diversifolia Hemsl (TD) and agro-industrial wastes of pyrethrum marc (PM) and tea residue (Tres) on RKN. Greenhouse experiments were conducted to determine the optimum levels of amending soils with TD, PM, vegetable waxy resins (VWR), Tres and cattle manure (CM) at their respective rates for management of RKN. The amendments were incorporated into the soil 14 days before sowing the seeds. Thereafter 21-day-old seedlings were inoculated with ten egg-masses, with four replications arranged in randomized complete block design. Plant growth and disease parameters were assessed and subjected to ANOVA. Disease severity and population reduced significantly at levels 2 and 3 for most amendments with the highest top biomass recorded in CM, TD and PM. Higher levels of Tres and VWR caused stunting and reduced biomass. Lower severity occurred in VWR, Tres, PM, and CM at 20\%, 28.0, 9.0, and $9.0 \mathrm{~g} / \mathrm{kg}$ soil, respectively, with reproduction ranging from 0.3 to 3.7 recorded on amended soils with Tres at $32.0 \mathrm{~g} / \mathrm{kg}$, TD at $8 \mathrm{~g} / \mathrm{kg}$ soil and $\mathrm{CM}$ at $9.0 \mathrm{~g} / \mathrm{kg}$. Higher yields, lower severity and reproduction were found on soil with PM, Tres, TD, CM and VWR at 9.0, 28.0, 8.0, 9.0 g/kg soil, and 20.0\%, respectively. These amendments are alternatives in ecofriendly management of RKN and other plant parasitic nematodes.
\end{abstract}

\section{Introduction}

Black nightshades are among the vegetable crops widely cultivated in Kenya. They are the source of income for the rural farmers and are rich in minerals including calcium, iron, and vitamins $[1,2]$. They have medicinal attributes that are associated with treatment of ear infections, tonic for babies and for management of HIV/AIDs [2-4]. The seeds of black nightshades are used for pigment extraction for making dyes [5].

Production of black nightshades is constrained by inadequate land, insect pests, diseases, and nematodes. So far, 13 nematode species including root-knot nematodes (RKNs) have been reported to attack black nightshades [6]. Rootknot nematode causes yield losses of up to 60\% [7].

Effective management of RKN has been through the use of nematicides. However, nematicides are being phased out of the market due to their adverse effects to the ecosystem and human being [8]. Eco-friendly non-chemical alternatives for the management of RKN have been reported in other vegetable crops [9-11]. Animal manure and agro-industrial wastes of tea [Camellia sinensis residue (Tres)] have been used for the management of RKN in grapevines [12]. Tithonia diversifolia (TD) is used in soil fertility improvement in maize production in Western Kenya as described by Jama et al. [13] as well as an antagonistic plant to RKN in bean production in Kenya [14]. Studies conducted in Western Kenya by Abuktsa-Onyango [15] reported the incorporation of CM, GM and TD into the soil for production of African indigenous leafy vegetables. However, nematicidal efficacy of these materials to RKN and other pythopathogenic nematodes in black nightshadehas not been reported. Plant extracts from fresh leaves of pyrethrum were tested in Egypt for their efficacy on M. incognita in eggplant at the rates of 0 , 
$0.5,2.5$ and $5 \%$ [16]. The extract caused $67 \%$ mortality at $5 \%$ rate in RKN as described by Hasabo and Noweer [16]. There is no information available on the efficacy of agro-industrial wastes of pyrethrum (Chrysanthemum cinerariafolium Vis.) [vegetable waxy resins (VWR) and Pymarc (PM)] for the management of RKN on black nightshade. These materials are cheap and locally available in rural farm areas of Kisii and Kilgoris counties of Kenya. In addition, PM is used as animal feed in Kenya while Tres is either thrown away or burnt in most tea factories. These materials can be utilized positively for black nightshade production.

This study focuses on evaluating the efficacy of agroindustrial wastes (Tres, Trej, PM and VWR) and organic amendments (TD, GM and CM) as well as optimizing their use for the management of RKN on black nightshadeby the rural poor-resource farmer.

\section{Methodology}

\subsection{Preparation Of Organic Materials and Growth Medium}

2.1.1. Greenhouse Experiment 1. The organic materials were collected from potential farmers in Kisii County with the aim of reducing agro-industrial waste accumulation as well as reducing overreliance on chemical fertilizers and pesticides for the production of black nightshade. Tea residues (Tres) and Trej were collected from Kiamokama tea factory and incorporated as shown in Table 1 [12], while T. diversifolia (TD) tender shoots were cut from the hedge, dried under shade, and ground and incorporated as indicated in Table 1 according to Jama et al. [13]. Well-decomposed cattle manure $(\mathrm{CM})$ and goat manure $(\mathrm{GM})$ were collected from the farmers, sun dried, and then incorporated into the soil as indicated in Table 1.

2.1.2. Greenhouse Experiment 2. This study was conducted using, CM, Tres, TD, VWR ethanol extract and PM organic amendments (OA) at different levels, slightly above or below the recommended rates to determine their efficacy on RKN as indicated in Table 1.

Twenty grams $(20 \mathrm{~g})$ of VWR paste were placed in a $150 \mathrm{~mL}$ beaker with $80 \mathrm{~mL}$ of ethanol and stirred thoroughly for ten minutes. The mixture was left for 24 hours after which it was stirred and decanted carefully forming a standard (S) solution $(100 \%)$ from which other dilutions were obtained by adding requisite amount of distilled water at the time of experiment.

Red soil and sand mixture $(2: 1)$ was sieved through a $3 \mathrm{~mm}$ pore size sieve, mixed thoroughly, and then steam sterilized at $121^{\circ} \mathrm{C}$ for 15 minutes. Thereafter, the sandy soil was mixed thoroughly with the various organic amendments at their respective rates in a one kilogram plastic pot. The pots were replicated four times with nonamended pots serving as control. The setup was arranged in randomized complete block design and watered regularly for fourteen days.

2.2. Field Experiment. The treatment combinations mentioned in Section 2.1.1 were used in the field test. The field was cleared, cultivated, ploughed, and divided into 48 plots each measuring $1.2 \times 3.2 \mathrm{~m}$. The plots were then treated as, no manure, Tres, Trej, CM, GM, TD, and mocap nematicides (M) as a reference control at their respective rates as shown in Table 1 . In addition, the treatments were also combined with mocap $(\mathrm{CM}+\mathrm{M}$, GM + M, Tres + M, Trej + M, TD + $\mathrm{M})$ at their respective rates. All the treatments were arranged in a RCBD with four replications. All plots were planted with Solanum nigrum green berried (SG) seedlings 14 days after incorporation of amendments into the soil. Each plot had 10 rows with each row having 6 plant units at a spacing of 15 $\times 30 \mathrm{~cm}$ giving a total of 60 plant units per plot. Mechanical weeding was done to ensure the plots were weed-free.

2.3. Inoculation Procedure. A three-week-old seedling of black nightshade was planted in each of the amended pots and watered regularly for seven days. Thereafter, four pots for each level of OA were inoculated with ten egg masses placed at the rhizosphere zone in the treated pots as describe here: cattle manure $(\mathrm{CM})+$ nematode inoculum $(\mathrm{N})$ at the rate of $6 \mathrm{~g} / \mathrm{kg}$ soil, CM-N, tea residue (Tres) $+\mathrm{N}$ at the rate of $28.5 \mathrm{~g} / \mathrm{kg}$ soil, Tres- $\mathrm{N}, T$. diversifolia $(\mathrm{TD})+\mathrm{N}$ at the rate of $5 \mathrm{~g} / \mathrm{kg}$ soil each, TD-N, pymarc $(\mathrm{PM})+\mathrm{N}$ at the rate of $6 \mathrm{~g} / \mathrm{kg}$ soil each, PM-N, goat manure $(\mathrm{GM})+\mathrm{N}$ at the rate of $6 \mathrm{~g} / \mathrm{kg}$ soil each, GM-N, no amendment (NA) + N, NA-N treatments replicated four times. Unamended and uninoculated pots served as controls in this experiment. The test was terminated 60 days after inoculation.

2.4. Physicochemical Properties of OAs. The amendments were analyzed for their physic-chemical properties at the National Agricultural Research Laboratories. The results are shown in Table 2.

\subsection{Data Collection}

2.5.1. Plant Growth Parameters. At the end of the experimental period, shoot heights were measured from the first basal node to the last apical node, and, thereafter, the plants gently uprooted, shoots separated from the roots, and their fresh weight determined. Soil was gently shaken off the roots, and thereafter the roots gently washed with tap water to remove adhering soil and then blotted dry with a paper towel before determining their weights.

2.5.2. Galling Index (GI). The root was spread on a paper towel, blotted dry, and scored for gall index on a $0-5$ gall rating scale according to Quesenberry et al. [17] where: $0=$ no galls, $1=1-2,2=3-10,3=11-30,4=31-100$, and $5 \geq 100$ galls per root system.

2.5.3. Extraction Of J2 from Soil. The soil was thoroughly but gently mixed, and a 200 cubic centimetre (cc) subsample taken for assessing nematode population using modified extraction tray method according to Hooper et al. [18]. The soil was spread on a double layer of paper towel supported by a plastic sieve and placed over a shallow extraction tray after which water was gently added to the sides until the soil 
TABLE 1: Treatment application rates in greenhouse and field experiments.

\begin{tabular}{lccc}
\hline \multicolumn{4}{c}{ Organic amendment application rates in greenhouse and field experiments } \\
Treatment & GH 1 (g/kg soil) & GH 2 (g/kg soil $)$ & Field experiment $(\mathrm{kg} / \mathrm{plot})$ or $(\mathrm{t} / \mathrm{ha})$ \\
\hline $\mathrm{CM}$ & 6 & $0,3,6$, and 9 & $2[5]$ \\
$\mathrm{GM}$ & 6 & $0,3,6$, and 9 & $2[5]$ \\
$\mathrm{TD}$ & 5 & $0,2.5,5$, and 8 & $1.5[4]$ \\
Trej & 28.5 & $0,14,28$, and 32 & $9[25]$ \\
Tres & 28.5 & $0,14,28$, and 32 & $9[25]$ \\
PM & - & $0,3,6$, and 9 & - \\
VWR & - & $0,20,60$, and 100 & - \\
Mocap** & - & - & $0.036[0.1]$ \\
Unamended & 0 & 0 & $0[0]$ \\
\hline
\end{tabular}

GH 1: greenhouse test 1; GH 2: greenhouse test 2; CM: cattle manure; GM: goat manure; TD: Tithonia diversifolia; Trej: tea rejects; Tres: tea residue; PM: pyrethrum marc; VWR: vegetable waxy resins.

$*$ VWR rate of application was measured in percentage.

** Mocap treatment used as a reference control in field test.

— Treatment not subjected to test conditions.

was just wet. The setup was left for 24 hours after which the contents from the extraction tray were placed into a $200 \mathrm{~mL}$ beaker and poured through a $38 \mu \mathrm{m}$ pore size sieve held at $45^{\circ}$ and then back washed with water from a wash water bottle into a $50 \mathrm{~mL}$ beaker. Excess water was sucked off with a dropper to reduce nematode suspension to $20 \mathrm{~mL}$ and nematodes enumerated over a stereomicroscope.

2.5.4. Reproductive Factor. The nematode reproduction factor (Rf) was determined by expressing final nematode egg masses/root system $\left(\mathrm{P}_{f}\right)$ as the ratio of the initial inoculum $\left(\mathrm{P}_{i}\right)$ of 10 egg masses [19].

2.6. Data Analysis. The data was subjected to analysis of variance (ANOVA) with all numerical data transformed $\left(\log _{10} X+1\right)$ where $X$ is galling index (GI) or the $J 2 / 200 \mathrm{~cm}^{3}$ soil) and thereafter subjected to ANOVA. Means were compared with the Least Significant Differences (LSD) test $(P=0.05)$. Correlation analysis between the plant growth parameters and nematodes populations in the soil and the GI was determined.

\section{Results}

\subsection{Effect of OAs on Plant Growth}

3.1.1. Shoot Height in Greenhouse Test 1. There was no significant difference $(P>0.05)$ among the amendments (Table 3). Tithonia diversifolia, Trej, and GM amendments on inoculated soils had some of the higher SH that did not differ significantly from that of plants in unamended inoculated soils (Table 3). Although Tres and CM had lower $\mathrm{SH}$, they were not significantly lower than that of unamended inoculated soils. However, the SH differed significantly $(P<$ 0.05 ) among the amendments in amended uninoculated plants (Table 3). Cattle manure and GM had some of the tallest shoots that differed significantly $(P<0.05)$ from that of plants grown in unamended and uninoculated soils
(Table 3). Although Trej and TD had higher SH, they did not differ significantly $(P<0.05)$ from unamended uninoculated soils (Table 3). The $\mathrm{SH}$ of plants grown in Tres, though being lower than that of plants grown in unamended and uninoculated soils did not differ significantly (Table 3). Plants grown in amended and uninoculated soils had higher SH mostly in CM, GM and Trej with that of CM being significantly taller $(P<0.05)$. All the other amendments in inoculated soils had higher $\mathrm{SH}$ that did not differ significantly from that of amended, and uninoculated soils (Table 3).

3.1.2. Fresh Shoot Weight in Greenhouse Test 1. The FSW did not differ significantly $(P>0.05)$ among the amendments (Table 3). Tithonia diversifolia and GM amended and inoculated soils had higher FSW that did not differ significantly $(P>0.05)$ from that of plants grown in unamended inoculated soils (Table 3). Although FSW of plants grown in Trej, CM and Tres amended and inoculated soils were low, they did not differ significantly $(P>0.05)$ from that of unamended and inoculated soils (Table 3). On the other hand, the amendments did not differ significantly on their effect on FSW in amended and uninoculated soils. Cattle manure had some of the higher FSW that did not differ significantly $(P>0.05)$ from unamended and uninoculated soils. Although FSW of all the other amendments were generally low, they did not differ significantly from that of unamended and uninoculated soils. The FSW of plants in amended and uninoculated soils were generally higher than that of amended and inoculated soils although they did not differ significantly $(P>0.05)$ (Table 3$)$. Correlation analysis $(r=-0.275, P>0.05)$ revealed a negative relationship between the J2 populations and the FSW although there was no significant difference established (Figure 1).

3.1.3. Fresh Root Weight in Greenhouse Test 1. The treatments did not differ significantly $(P>0.05)$ on their effect on FRW among the amendments (Table 3). The FRW in all amended 
TABLE 2: Physicochemical properties* of plant tissue and animal manure used for amending soil in greenhouse and field experiments.

\begin{tabular}{|c|c|c|c|c|c|}
\hline \multirow{2}{*}{ Sample description } & \multicolumn{5}{|c|}{ Organic manure analysis data } \\
\hline & GM & $\mathrm{CM}$ & Trej & Tres & TD \\
\hline pH-water $(1: 2.5)$ & 7.77 & 7.34 & 6.96 & 5.83 & 6.30 \\
\hline Org. carbon \% & 3.15 & 3.70 & 3.81 & 3.91 & 4.26 \\
\hline Nitrogen \% & 1.05 & 1.05 & 4.20 & 4.10 & 5.25 \\
\hline $\mathrm{C} / \mathrm{N}$ ratio & $3: 1$ & $3.5: 1$ & $0.91: 1$ & $0.95: 1$ & $0.81: 1$ \\
\hline Phosphorus \% & 0.27 & 0.21 & 0.25 & 0.52 & 0.28 \\
\hline Potassium \% & 1.58 & 1.58 & 1.92 & 0.13 & 1.65 \\
\hline Calcium \% & 4.36 & 0.96 & 2.09 & 2.13 & 0.59 \\
\hline Magnesium \% & 0.33 & 0.08 & 0.34 & 0.26 & 0.19 \\
\hline Iron mg/kg & 3767 & 1397 & 1315 & 1297 & 2033 \\
\hline Copper mg/kg & 15.0 & 3.3 & 3.67 & 3.58 & 8.33 \\
\hline Manganese mg/kg & 2083 & 892 & 1020 & 1026 & 1040 \\
\hline Zinc mg/kg & 307 & 85 & 82 & 79 & 78 \\
\hline
\end{tabular}

*Physicochemical analysis done at National Agricultural Research laboratories (KARI-NARL) in Kenya.

TABLE 3: Comparative efficacy of agro-industrial wastes and OAs on growth of SG in greenhouse test 1.

\begin{tabular}{|c|c|c|c|c|c|c|}
\hline \multirow{3}{*}{ Amendment } & \multicolumn{6}{|c|}{ Efficacy of treatments on SG growth in greenhouse test 1} \\
\hline & \multicolumn{2}{|c|}{$\mathrm{SH}(\mathrm{cm})$} & \multicolumn{2}{|c|}{ FSW $(\mathrm{gm})$} & \multicolumn{2}{|c|}{ FRW (gm) } \\
\hline & $+\mathrm{N}$ & $-\mathrm{N}$ & $+\mathrm{N}$ & $-\mathrm{N}$ & $+\mathrm{N}$ & $-\mathrm{N}$ \\
\hline GM & $49.25 \mathrm{abc}$ & $60.98 \mathrm{ab}$ & $18.75 \mathrm{ab}$ & $19.18 \mathrm{ab}$ & $1.9 \mathrm{ab}$ & $1.45 \mathrm{ab}$ \\
\hline $\mathrm{CM}$ & $44.0 \mathrm{~b}$ & $68.13 \mathrm{a}$ & $13.08 \mathrm{ab}$ & $22.64 \mathrm{a}$ & $1.75 \mathrm{ab}$ & $1.18 \mathrm{ab}$ \\
\hline Trej & $51.38 \mathrm{abc}$ & $52.0 \mathrm{abc}$ & $15.48 \mathrm{ab}$ & $22.0 \mathrm{a}$ & $0.99 b$ & $1.2 \mathrm{ab}$ \\
\hline TD & $52.75 \mathrm{abc}$ & $51.25 \mathrm{abc}$ & $18.65 \mathrm{ab}$ & $18.23 \mathrm{ab}$ & $1.6 \mathrm{ab}$ & $2.7 \mathrm{a}$ \\
\hline Tres & $42.25 b c$ & $34.5 \mathrm{c}$ & $8.58 \mathrm{~b}$ & $14.9 \mathrm{ab}$ & $1.1 \mathrm{ab}$ & $0.89 \mathrm{~b}$ \\
\hline Unamended & $38.0 \mathrm{bc}$ & $47.13 b c$ & $15.83 \mathrm{ab}$ & $22.03 a$ & $1.95 \mathrm{ab}$ & $1.1 \mathrm{ab}$ \\
\hline$P$ value & 0.736 & 0.000 & 0.235 & 0.585 & 0.728 & 0.034 \\
\hline
\end{tabular}

Means followed by similar letter (s) are not significantly different $(P>0.05)$.

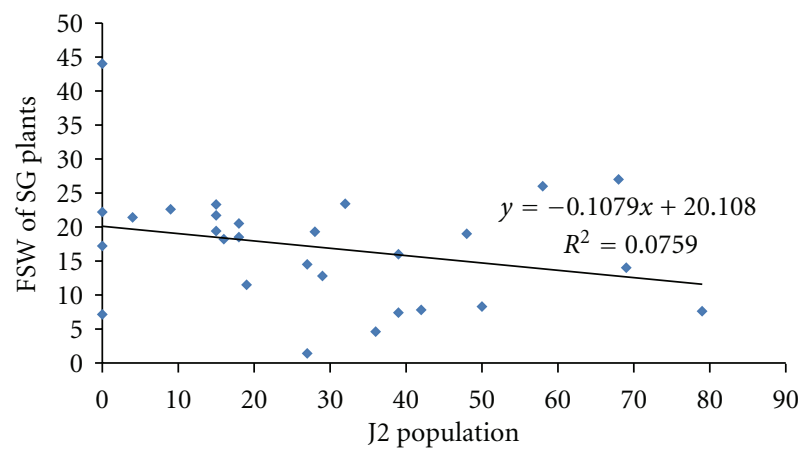

Figure 1: Relationship between FSW and J2 populations in greenhouse test 1 .

and inoculated soils was lower than that of unamended and inoculated soils although they did not differ significantly $(P>0.05)$. The FRW of amended uninoculated plants differed significantly $(P<0.05)$ among the amendments (Table 3). Heavier roots that did not differ significantly $(P>0.05)$ from unamended and uninoculated soils were found in plants grown on TD, GM, CM and Trej amended and uninoculated soils. The FRW of plants grown on

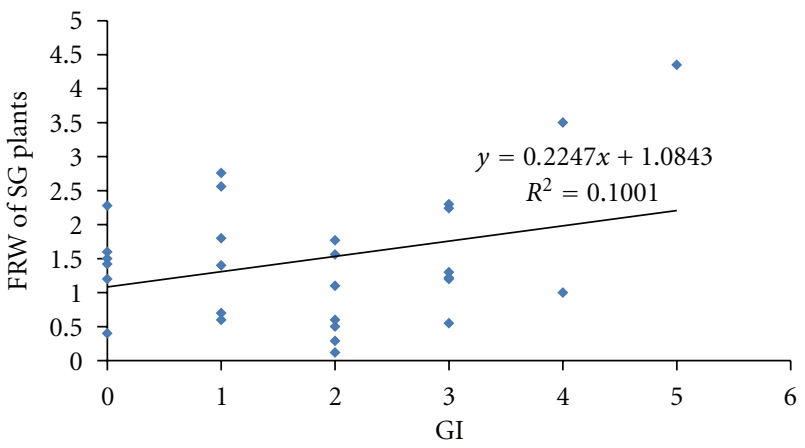

FIgURE 2: Relationship between FRW and GI in greenhouse test 1.

Tres though lower did not differ significantly from that of unamended and uninoculated soils (Table 3). Although the FRW of amended and inoculated soils was generally higher, they did not differ significantly from that of amended and uninoculated soils. Further analysis revealed a positive correlation $(r=0.316, P>0.05)$ between the J2 population and GI though there was no significant difference established (Figure 2). 


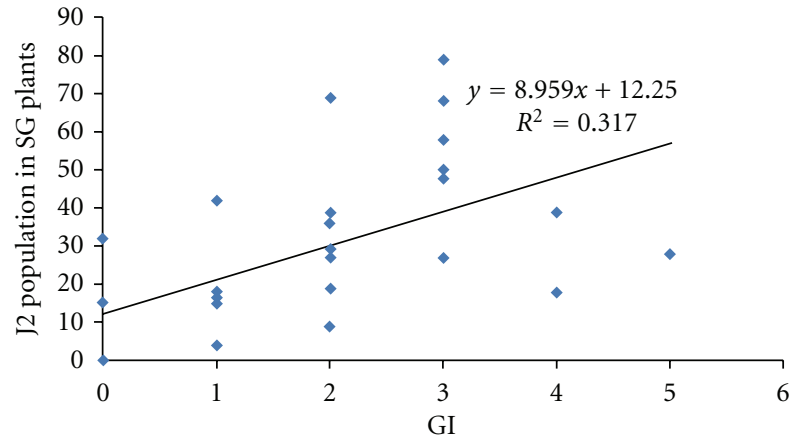

FIGURE 3: Relationship between J2 population and GI in greenhouse test 1.

3.1.4. J2 Population, GI, and Rf in Greenhouse Test 1. The amendments differed significantly $(P<0.05)$ on their suppression on J2 population, in soil (Table 4). All the amendments had lower J2 population with TD and Trej having significantly lower J2 than that of unamended and inoculated soils. Although GM, CM and Tres suppressed J2 population the J2s were not significantly lower than that of unamended and inoculated soils (Table 4).

There was a significant difference $(P<0.05)$ on GI among the amendments (Table 4). The GI of plants in Trej-, TD, and Tres-amended and inoculated soils was lower than that of unamended and inoculated soils though they did not differ significantly $(P>0.05)$. Although the GI in plants grown on CM and GM was higher, there was no significant difference established from that of unamended and inoculated soils (Table 4). Further analysis revealed a significant positive correlation $(r=0.563, P<0.05)$ between the J2 populations and GI (Figure 3 ).

The Rf differed significantly $(P<0.05)$ among the amendments (Table 4). Tithonia diversifolia, Trej, and Tres had some of the lowest Rf, with TD having the lowest although there was no significant difference $(P>0.05)$ established from that of plants grown on unamended inoculated soils (Table 3). The highest Rf was found in GM and CM though there was no significant difference established $(P>0.05)$ from that of unamended inoculated soils (Table 4 ).

\subsection{Greenhouse Test 2}

3.2.1. Shoot Height in Greenhouse Test 2. The results revealed that all five treatments decreased the nematode infestation and improved plant growth of black nightshade. The $\mathrm{SH}$ differed significantly $(P<0.05)$ among the different levels in TD amended and inoculated plants (Table 5). Except soils amended with $\mathrm{TD}$ at $2.5 \mathrm{~g} / \mathrm{kg}$ soil, those amended at 5 and $8 \mathrm{~g} / \mathrm{kg}$ soil had significantly $(P<0.05)$ higher $\mathrm{SH}$ than those in unamended and inoculated soils (Table 5). The SH in amended and uninoculated plants at levels 24 were significantly higher than those of unamended and uninoculated soils (Table 5).

In $\mathrm{PM}$, there was significant difference $(P<0.05)$ established from unamended and inoculated soils with soils amended at $6 \mathrm{~g} / \mathrm{kg}$ having the tallest shoots than that of unamended and inoculated soils. On the other hand, the SH differed significantly $(P<0.05)$ from that of unamended and uninoculated soils. Soils amended at $9 \mathrm{~g} / \mathrm{kg}$ had some of the taller shoots while that at $3 \mathrm{~g} / \mathrm{kg}$ soil had the least. However, $\mathrm{SH}$ in these levels differed significantly $(P<0.05)$ from that of unamended and uninoculated soils (Table 5).

The SH of plants grown on Tres-amended and -inoculated soils differed significantly $(P<0.05)$ among the levels (Table 5). Those amended at $28 \mathrm{~g} / \mathrm{kg}$ soil had significantly taller shoots than that of unamended and inoculated soils. However, plants grown on soils amended with $32 \mathrm{~g} / \mathrm{kg}$ soil were found to be shorter than those at 14 and $28 \mathrm{~g} / \mathrm{kg}$ soil, respectively, although they were significantly taller than that of unamended and inoculated soils (Table 5). In amended but uninoculated soils, there was significant difference $(P<0.05)$ established among the levels of treatment. Plants grown on soils amended at 14 and $28 \mathrm{~g} / \mathrm{kg}$ soil had some of the taller shoots while at higher rate ( $32 \mathrm{~g} / \mathrm{kg}$ soil) the $\mathrm{SH}$ was reduced although the plants were significantly taller than that of unamended and uninoculated soils (Table 5 ).

Although the $\mathrm{SH}$ of plants grown on $\mathrm{CM}$-amended and -inoculated soils were higher, those amended at $3 \mathrm{~g} / \mathrm{kg}$ soil were not significantly higher compared to that of unamended and inoculated soils. At the rate of 6 and $9 \mathrm{~g} / \mathrm{kg}$ soils, the SH were significantly $(P<0.05)$ higher than that of unamended and inoculated soils (Table 5). On the other hand, significantly taller shoots were recorded among the levels in amended and uninoculated soils, with higher rate of amendment having significantly taller shoots than that of unamended and uninoculated soils.

All the levels in amended inoculated plants grown on VWR amended soils did not differ significantly $(P>0.05)$ (Table 5). Although the $\mathrm{SH}$ of plants grown on soils amended at $20 \%$ and $60 \%$ were higher, they did not differ significantly from that of unamended and inoculated soils. However, the $\mathrm{SH}$ of plants grown on soils amended and inoculated soils at $100 \%$ of VWR had shorter shoots that did not differ significantly $(P>0.05)$ from that of unamended and inoculated soils (Table 5). Plants grown in amended and uninoculated soils had SH that did not differ significantly from that of unamended and uninoculated soils (Table 5). Although plants grown on soils amended at $20 \%$ had taller shoots, they were not significantly taller than that of unamended and uninoculated soils. Soils amended at $60 \%$ and $100 \%$ had shorter shoots that were not significantly shorter than that of unamended and uninoculated soils (Table 5).

3.2.2. Fresh Shoot Weight in Greenhouse Test 2. The various amendments differed significantly $(P<0.05)$ on their effect on FSW in plants grown on amended and inoculated soils (Table 5). In TD, the soils amended at 5 and $8 \mathrm{~g} / \mathrm{kg}$ soil had higher FSW that did not differ significantly $(P>0.05)$ from that of unamended and inoculated soils. However, soils amended at $2.5 \mathrm{~g} / \mathrm{kg}$ soil had some of the lower FSW that did not differ significantly from the unamended and inoculated soil (Table 5). The FSW in amended and uninoculated 
soils did not differ significantly from the unamended and uninoculated soils. Soils amended at 5 and $8 \mathrm{~g} / \mathrm{kg}$ soil had higher FSW that did not differ significantly $(P>0.05)$ from that of unamended and uninoculated soils. Although soils amended at 2.5 had lower FSW, they were not significantly lower than that of unamended and uninoculated soils (Table 5). Although amended and uninoculated soils had relatively higher FSW, they did not differ significantly from that of amended and inoculated soils.

The FSW in amended and inoculated plants among the levels of amendment in PM did not differ significantly $(P>$ 0.05 ) from that of unamended and inoculated soils (Table 5). The FSW in soils amended at 6 and $9 \mathrm{~g} / \mathrm{kg}$ soils were higher though not significantly higher than that of unamended and inoculated soils. Similarly, soils amended at $3 \mathrm{~g} / \mathrm{kg}$ soil had some of the lower FSW that were not significantly lower than that of unamended and inoculated soils (Table 5). On the other hand, the FSW of plants grown on amended and uninoculated soils were higher though not significantly $(P>$ 0.05 ) higher than that of unamended and uninoculated soils. Although amended and uninoculated soils had higher FSW, they were not significantly higher than that of unamended and inoculated soils.

Tres-inoculated and -amended soils had some of the highest FSW that differed significantly $(P<0.05)$ from that of unamended and inoculated soils with those amended at $28 \mathrm{~g} / \mathrm{kg}$ soil having the highest FSW (Table 5). On the other hand, all the levels on amended and uninoculated soils on Tres had significantly $(P<0.05)$ higher FSW than that of unamended and uninoculated soils (Table 5). Except for soils amended at $28 \mathrm{~g} / \mathrm{kg}$ soil, those of amended and uninoculated soils had generally higher FSW that did not differ significantly $(P>0.05)$ from that of amended and inoculated soils (Table 5).

Although the FSW in CM amended and inoculated soils was lower, they were not significantly $(P>0.05)$ lower than that of unamended and inoculated soils (Table 5). On the other hand, the FSW of amended and uninoculated soils at the rate of 3 and $6 \mathrm{~g} / \mathrm{kg}$ soil were significantly lower than that of unamended and uninoculated soils. However, soils amended at $9 \mathrm{~g} / \mathrm{kg}$ soil had higher FSW that did not differ significantly $(P>0.05)$ from that of unamended and uninoculated soil (Table 5). Generally, amended and uninoculated soils had higher FSW that did not differ significantly $(P>0.05)$ from that of unamended and inoculated soils except for the soils amended at $9 \mathrm{~g} / \mathrm{kg}$ soil that differed significantly.

The FSW of different levels of VWR did not differ significantly $(P>0.05)$ from that of unamended and inoculated soils (Table 5). Higher FSW was found at $60 \%$ rate with higher rates $(100 \%)$ having lower FSW. On the other hand, unamended and uninoculated soils amended with VWR at the rate of $60 \%$ and $100 \%$ were significantly $(P<0.05)$ lower than that of unamended and uninoculated soils with those amended at 100\% having the lowest FSW (Table 5). Although the soils amended and uninoculated at the rate of $20 \%$ had some of the lowest FSW, they did not differ significantly $(P>0.05)$ from that of unamended and uninoculated soils (Table 5). Unamended and uninoculated soils had higher FSW that did not differ significantly $(P>$ $0.05)$ from that of unamended and inoculated soils. Except for amended and inoculated soils at $20 \%$ that had lower FSW, those at $60 \%$ and $100 \%$ had higher FSW that were not significantly higher than that of amended and uninoculated soils (Table 5). Of the amendments, Tres, PM, and TD were the best in improving FSW and suppressing RKN on black nightshade.

3.2.3. Fresh Root Weight in Greenhouse Test 2. The various treatments differed significantly $(P<0.05)$ on their effect on FRW (Table 5). On TD, amended and inoculated soils at 2.5 and $5.0 \mathrm{~g} / \mathrm{kg}$ soil had some of the lower FRW that did not differ significantly $(P>0.05)$ from that of unamended and inoculated soils (Table 5). Although soils amended at $8 \mathrm{~g} / \mathrm{kg}$ soil had higher FRW, they were not significantly higher than that of unamended and inoculated soils. On the other hand, amended and uninoculated soils at the rate of $2.5 \mathrm{~g} / \mathrm{kg}$ soil had lower FRW though not significantly lower than that of unamended and uninoculated soils. However, those amended at the rate of 5 and $8 \mathrm{~g} / \mathrm{kg}$ soil had some of the higher FRW that differed significantly $(P<0.05)$ from that of unamended and uninoculated soils (Table 5). The FRW of amended and uninoculated soils was found to be significantly higher, except for those of soils amended at $2.5 \mathrm{~g} / \mathrm{kg}$ soil that did not differ significantly from those of amended and inoculated soils.

In PM, FRW of plants grown on amended and inoculated soils was higher although they did not differ significantly $(P>0.05)$ from that of unamended and inoculated soils. Those of plants grown on amended and uninoculated soils were significantly higher than that of unamended and uninoculated soils with those amended at $9 \mathrm{~g} / \mathrm{kg}$ soil having the highest FRW (Table 5). Although amended and uninoculated soils had higher FRW than that of amended and inoculated soils, those amended at $9 \mathrm{~g} / \mathrm{kg}$ soil had significantly higher FRW (Table 5).

Although Tres-amended and -inoculated soils had higher FRW that did not differ significantly $(P>0.05)$ from that of unamended and inoculated soils, heavier roots were found at $14 \mathrm{~g} / \mathrm{kg}$ soil with higher rate reducing FRW. On the other hand, amended and uninoculated soils on Tres amendment had significantly higher FRW than that of unamended and uninoculated soils with significantly $(P<0.05)$, heavier roots were found at $28 \mathrm{~g} / \mathrm{kg}$ soil with higher rate reducing FRW (Table 5). Amended and uninoculated soils had significantly heavier roots at the rates of 28 and $32 \mathrm{~g} / \mathrm{kg}$ soil than that of amended and inoculated soils although soils amended at $14 \mathrm{~g} / \mathrm{kg}$ soil did not differ significantly $(P>0.05)$.

Except for plants grown on CM-inoculated and -amended soils at $9 \mathrm{~g} / \mathrm{kg}$ soil that had higher FRW, those amended at 3 and $6 \mathrm{~g} / \mathrm{kg}$ soil had lower FRW that did not differ significantly from that of unamended and inoculated soils (Table 5). On the other hand, amended and uninoculated soils had lower FRW that did not differ significantly $(P>$ $0.05)$ from that of unamended and uninoculated soils (Table 5). Although amended and uninoculated soils had higher FRW, they were not significantly higher than that of amended and inoculated soils (Table 5). 
The FRW of plants grown on VWR at $20 \%$ were significantly $(P<0.05)$ higher than that of unamended and inoculated soils although there was no significant difference established on those soils amended at 60 and $100 \%$ in inoculated soils (Table 5). Similarly, VWR at 20\% in amended and uninoculated soils had significantly higher FRW than that of unamended and uninoculated soils. At higher rates, amended and uninoculated soils had lower FRW that were not significantly $(P>0.05)$ lower than that of unamended and uninoculated soils (Table 5). Although plants grown on amended and uninoculated soils had higher FRW, they were not significantly higher than that of amended and inoculated soils (Table 5).

3.2.4. The J2 Population in Greenhouse Test 2. The nematode population differed significantly $(P<0.05)$ among the amendments. In soils treated with $\mathrm{TD}$, higher $\mathrm{J} 2$ suppression was found at the rate of $8 \mathrm{~g} / \mathrm{kg}$ soil although it did not differ significantly from that of unamended and inoculated soils (Table 5). All the other rates in TD had lower J2 populations that did not differ significantly from unamended and inoculated control.

The J2 in amended and inoculated soils treated with PM differed significantly from that of unamended and inoculated soils with those amended at $9 \mathrm{~g} / \mathrm{kg}$ soil being the most suppressive, followed by those at $6 \mathrm{~g} / \mathrm{kg}$ soil while those amended at $3 \mathrm{~g} / \mathrm{kg}$ soil were the least suppressive (Table 5). Tea residue had some of the lower J2 populations that differed significantly $(P<0.05)$ from that of unamended and inoculated soils. The most suppressive rate of application was $32 \mathrm{~g} / \mathrm{kg}$ soil followed by $28 \mathrm{~g} / \mathrm{kg}$ soil while $14 \mathrm{~g} / \mathrm{kg}$ soil was the least suppressive (Table 5).

Cattle manure suppressed $\mathrm{J} 2$ population with those soils amended at 6 and $9 \mathrm{~g} / \mathrm{kg}$ soil having significantly lower $\mathrm{J} 2$ population than that of unamended and inoculated soils. However, soils amended at $3 \mathrm{~g} / \mathrm{kg}$ soil had some of the lower J2 population that did not differ significantly from that of unamended and inoculated soils (Table 5).

Soils amended with VWR had significantly lower J2 populations than that of unamended and inoculated soils. Soils amended at $100 \%$ were the most suppressive, followed by those amended at $60 \%$ while those amended at $20 \%$ were the least suppressive (Table 5).

Of the amendments, PM, Tres, and VWR were the best amendments in suppressing RKN populations at level 2 of amendment. Cattle manure suppressed J2 population at level 3 while TD caused J2 suppression at higher rate of application.

3.2.5. The GI and Rf in Greenhouse Test 2. All the amendment levels differed significantly $(P<0.05)$ in suppressing galling index, with levels 2, 3 and 4 recording significantly lower GI than unamended and inoculated soils in all the amendments (Table 5). The soils amended with TD and PM were more suppressive to RKN at the rates of 8 and $9 \mathrm{~g} / \mathrm{kg}$ soil respectively with GI ranging from $1.0-1.5$ than that of unamended and inoculated soils $(\mathrm{GI}=4.8)$. However, at lower rate of amendment the GI was higher ranging from 3.0-3.3 although it was significantly lower than that of unamended and inoculated soils (Table 5). Soils amended withTres, CM and VWR suppressed J2 population at level 3 and 4 of amendment with GI ranging from 1.0-2.5 than that of unamended and inoculated soils. At level 2 of amendment, higher GI was obtained although it was significantly lower than that of unamended and inoculated soils (Table 5).

Reproduction of RKN differed significantly $(P<0.05)$ among the amendments. Plants grown on Tres, CM and VWR had some of the lower Rf that differed significantly from that of unamended and inoculated soils. Those grown on TD had reduced $\mathrm{Rf}$ at higher rate of amendment at $8 \mathrm{~g} / \mathrm{kg}$ soil. Of the amendments, Tres was the best organic amendment followed by CM while VWR and TD were the least. All the amendments had lower Rf at level 2-4 of application with level 4 recording the lowest $\mathrm{Rf}$ in all amendments compared to unamended and inoculated soils (Table 5).

3.3. Shoot Height in Field Test. A significant difference $(P<$ 0.05 ) was established among the various treatments in plants grown on amended soils without mocap (Figure 4). Soils amended with TD, Tres, CM, and Trej had some of the shoots that were significantly $(P<0.05)$ taller than those grown on unamended soils without mocap (Figure 4).

Although plants grown on GM-amended soils without mocap were taller, they did not differ significantly $(P>0.05)$ from those on unamended soils without mocap. On the other hand, the treatments on plants grown on amended soils with mocap were significantly different $(P<0.05)$.

Soils amended with CM, TD, and Tres had higher SH than unamended soils with mocap although they were not significantly different (Figure 4). Plants grown on Trej and GM had lower SH that did not differ significantly $(P>0.05)$ from that of unamended soils with mocap. Although plants grown on amended soils with mocap were generally taller than those on amended soils without mocap, those grown on TD and Tres amended soils with mocap were shorter though not significantly different from those on amended soils without mocap (Figure 4). Unamended soils with mocap had significantly taller shoots than unamended soils without mocap. Further analysis revealed negative correlation $(r=$ $-0.0 .548, P>0.05$ ) between the SH of SG plants with nematode GI although the relationship was not significantly different (Figure 5).

3.3.1. Fresh Shoot Weight in Field Test. There was a significant difference $(P<0.05)$ on FSW in amended plants without mocap (Figure 6). Plants grown on TD- and Tres-amended soils without mocap had higher FSW that differ significantly $(P<0.05)$ from those on unamended soils without mocap (Figure 6). Although soils amended with GM, CM, and Trej had higher FSW, they did not differ significantly $(P>0.05)$ from unamended soils without mocap. The treatments did not differ significantly $(P>0.05)$ on their effect on FSW on plants grown on amended soils with mocap (Figure 6). Although FSW of plants grown on TD and Tres amended with mocap was higher than those of plants grown on 


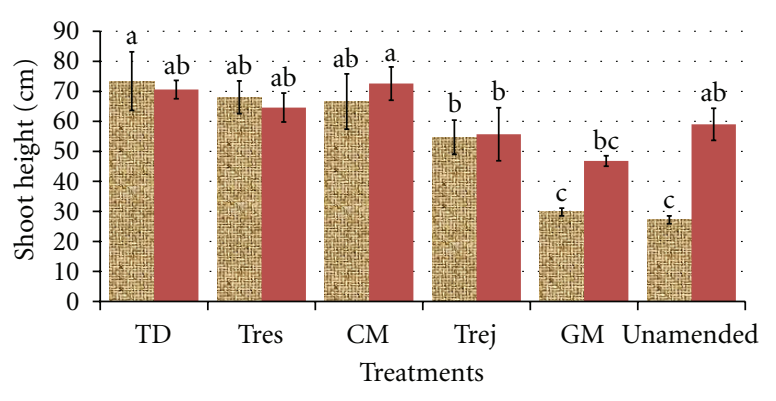

SG $-M$

a $\mathrm{SG}+\mathrm{M}$

Figure 4: Comparative efficacy of agro-industrial wastes of tea and OAs of TD, CM and GM on SH of SG plants in field test. Data are means \pm SE on SH of black nightshade from field test. Means followed by similar letter (s) are not significantly different $(P>0.05)$.

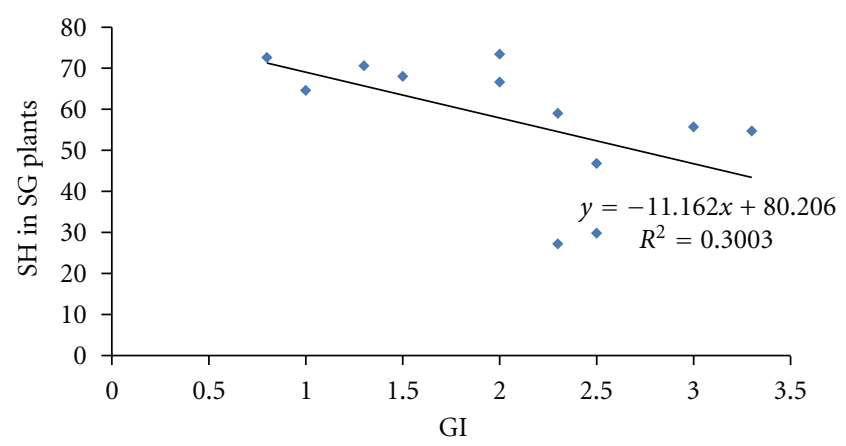

FIGURE 5: Effect of GI on shoot height of SG plants in field test.

unamended soils with mocap, they did not differ significantly $(P>0.05)$. The FSW of CM, GM, and Trej was lower than unamended soils with mocap although they did not differ significantly $(P>0.05)$. The FSW of plants grown on amended soils with mocap did not differ significantly from those grown on amended soils without mocap (Figure 6).

Unamended plants grown on soils with mocap were heavier than those grown on unamended soils without mocap although they did not differ significantly $(P>0.05)$. Correlation $(r=-0.103, P>0.05)$ analysis revealed a negative relationship between the FSW and nematode GI although there was no significant difference established (Figure 7).

3.3.2. Fresh Root Weight in Field Test. The treatments did not differ significantly $(P>0.05)$ on their effect on FRW among the plants grown on amended soils without mocap (Figure 8). All the amendments had heavier roots that did not differ significantly $(P>0.05)$ from unamended soils without mocap.

Tithonia diversifolia, Tres- and GM significantly $(P>$ 0.05 ) from that of unamended soils without mocap (Figure 8). On the other hand, FRW of plants grown in amended soils with mocap did not differ significantly $(P<0.05)$.

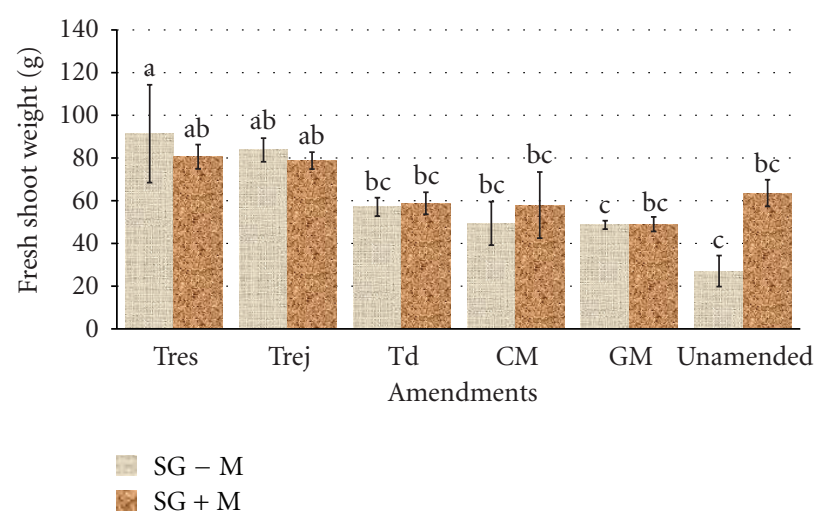

FIgURE 6: Comparative efficacy of agro-industrial wastes of tea and OAs of TD, CM and GM on FSW of SG plants in field test. Data are means \pm SE on SH of black nightshade from field test. Means followed by similar letter (s) are not significantly different $(P>0.05)$.

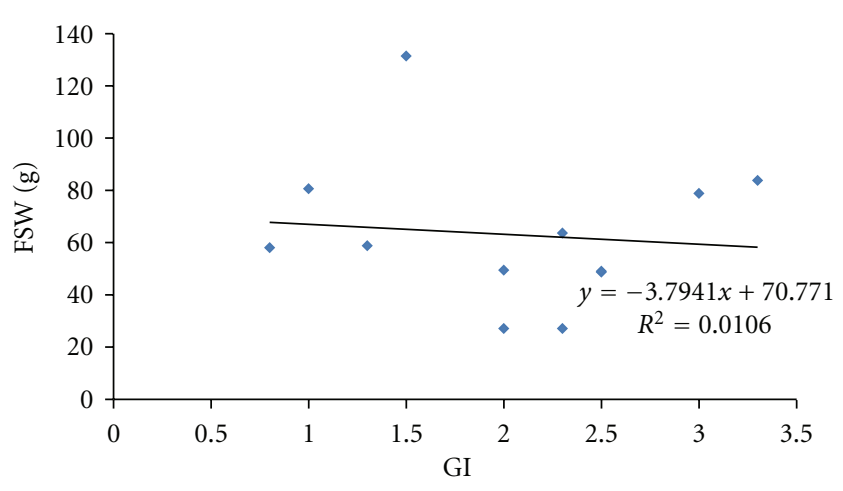

Figure 7: Effect of GI on fresh shoot weight of SG plants in field test.

The FRW was significantly higher in plants grown on Tres amended soils with mocap than those grown on unamended soils with mocap (Figure 8). Although GM, Trej, TD, and CM had higher FRW, they were not significantly higher than that of unamended plants with mocap (Figure 8). Amended plants with mocap had higher FRW although they were not significantly $(P>0.05)$ higher than that of amended plants grown on amended soils without mocap. Correlation analysis $(r=-0.619, P<0.05)$ revealed a significant negative trend between the FRW and the J2 population (Figure 9).

3.3.3. The J2 Population, GI and Rf in Field Test. There was a significant difference among the amendments on J2 population in amended soils without mocap (Table 6). Significantly $(P<0.05)$ lower $\mathrm{J} 2$ population was found in all amended soils without mocap TD, Tres, and Trej having some of the lower $\mathrm{J} 2$ populations that differed significantly from the unamended soils without mocap (Table 6). On the other hand, the J2 populations differed significantly $(P<0.05)$ among the treatments in amended soils with mocap. The J2 population in amended soils with mocap were 


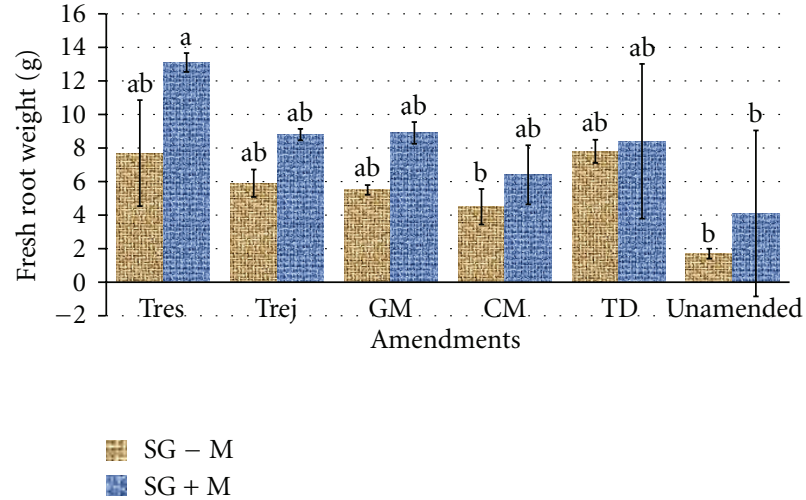

FIGURE 8: Comparative efficacy of agro-industrial wastes of tea and OAs on FRW of SG plants in field test. Data are means \pm SE on SH of black nightshade from field test. Means followed by similar letter (s) are not significantly different $(P>0.05)$.

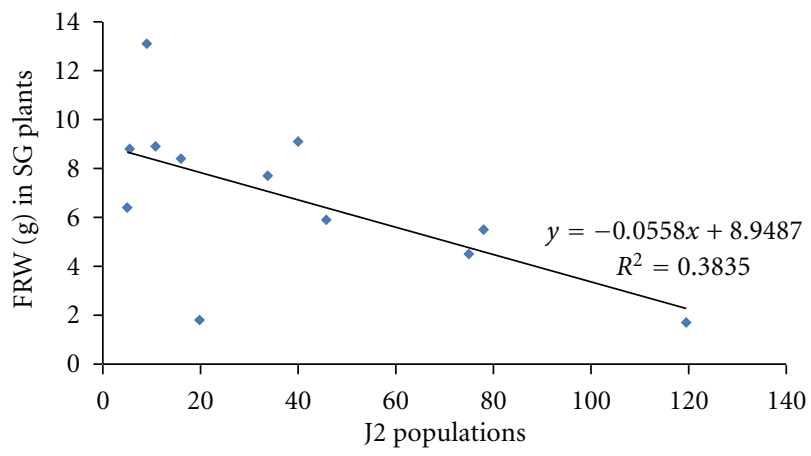

FIGURE 9: Effect of J2 on fresh root weight of SG plants in field test.

significantly suppressed than that of unamended soils with mocap (Table 6). Although amended soils with mocap had lower J2 populations, they did not differ significantly from that of amended soils without mocap (Table 6). However, the $\mathrm{J} 2$ population in unamended soils with mocap was significantly lower than that of unamended soils without mocap.

There was no significant difference in GI among the amendments $(P>0.05)$ in amended soils without mocap (Table 6). Although Tres, TD, CM, Trej, and GM amended soils without mocap had some of the lower GI, they did not differ significantly from unamended soils without mocap (Table 6). On the other hand, the GI differed significantly among the amendments in soils with mocap with CM having significantly lower GI than that of unamended soils with mocap (Table 6). Although the GI in Tres, TD, and Trej amended soils with mocap was lower, they did not differ significantly from that of unamended soils with mocap (Table 6). The GI in GM amended soils was generally higher though not significantly higher than that of unamended soils with mocap. Generally the GI in amended soils with mocap was lower though not significantly lower than that of unamended soils without mocap (Table 6). Further analysis revealed a positive correlation $(r=0.312, P>0.05)$

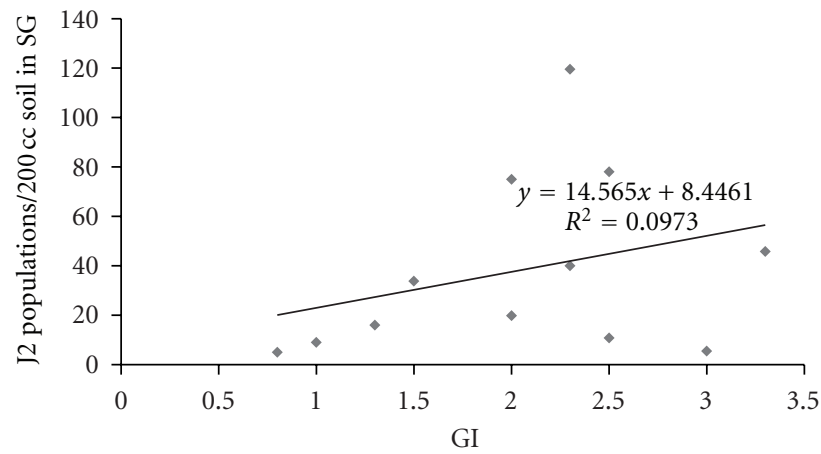

FIGURE 10: Relationship between the GI and J2 populations in the field test.

between the GI and the J2 population although there was no significant difference established (Figure 10). The various amendments differed significantly on suppressing $\mathrm{Rf}$ (Table 6). All the amendments had significantly $(P<0.05)$ lower Rf than unamended soils.

\section{Discussion}

The results revealed that amending soils with TD, GM, CM, and agro-industrial wastes of Tres, Trej, PM, and VWR suppressed RKN reproduction, galling and $\mathrm{J} 2$ population as well as promoted plant growth. The various OAs increased plant growth as depicted in Tables 3, 4, 5 and 6. Greenhouse test 1 revealed significant suppression of RKN population, GI and Rf in soils amended with agro-industrial wastes of tea, and those amended with TD. The significant suppression may be attributed to higher nitrogen content, narrow $\mathrm{C} / \mathrm{N}$ ratio, and lower potassium levels in these materials (Table 2). Moreover, higher nitrogen levels and narrow $\mathrm{C} / \mathrm{N}$ ratio have been associated with the production of toxic ammonia which is known to reduce nematode reproduction in soil as reported by Jama et al. [10, 11, 13]. Huber [20] and Oka [21] reported that amending soils with materials with narrow $\mathrm{C} / \mathrm{N}$ ratio and higher nitrogen content with lower potassium levels reduced galling and reproduction of RKN. The reduction in galling index and $\mathrm{Rf}$ on S. nigrum signifies the viability and efficacy of the materials tested in this study in management of RKN pests.

Greenhouse test 2 revealed a concomitant increase in plant growth parameters and suppression of RKN disease with increased rates of application in TD, PM, CM, and GM. However, tea residue and VWR caused stunting at higher rates despite having reduced RKN disease tremendously. The stunting effect in tea residue may be attributed to the presence of higher levels of phenolic compounds and tannins present in tea [12]. Studies in Chile revealed that tea residue causes necrosis in roots of grapevines at levels more than $28 \mathrm{~g} / \mathrm{kg}$ soil similar to the findings of this study [12]. However, when used on field test, stunting effect of tea residue and rejects was reduced as these materials promoted improved plant growth and suppression of RKN disease. The suppression of RKN may be attributed to dilution effect on 
TABLE 4: Effect of OAs and agro-industrial wastes on RKN in SG in the greenhouse test 1.

\begin{tabular}{|c|c|c|c|}
\hline Amendment & J2/200 cc soil & Galling index $(\mathrm{GI})^{*}$ & Reproduction factor (Rf) \\
\hline GM & $248.5 \mathrm{ab}$ & $3.0 \mathrm{a}$ & $3.44 \mathrm{a}$ \\
\hline $\mathrm{CM}$ & $288.8 \mathrm{ab}$ & $2.95 a$ & $4.2 \mathrm{a}$ \\
\hline Tres & $278.3 \mathrm{ab}$ & $1.5 \mathrm{abc}$ & $2.2 \mathrm{ab}$ \\
\hline $\mathrm{TD}$ & $14.3 \mathrm{c}$ & $1.3 \mathrm{bc}$ & $0.5 b c$ \\
\hline Trej & $171.5 b$ & $1.0 \mathrm{bc}$ & $1.23 \mathrm{~b}$ \\
\hline Unamended & $313.3 \mathrm{a}$ & $2.8 \mathrm{ab}$ & $3.03 \mathrm{ab}$ \\
\hline$P$ value & 0.000 & 0.001 & 0.000 \\
\hline
\end{tabular}

Means on the same column followed by similar letter $(\mathrm{s})$ are not significantly different $(P>0.05)$.

* Gall index on a $0-5$ gall rating scale according to Quesenberry et al. [17] where $0=$ no galls, $1=1-2,2=3-10,3=11-30,4=31-100$, and $5 \geq 100$ galls per root system.

TABLE 5: Effect of soil amendment with CM, TD, and agro-industrial wastes of tea and pyrethrum on the growth of black nightshade and RKN disease in greenhouse test 2.

\begin{tabular}{|c|c|c|c|c|c|c|c|c|c|c|}
\hline \multirow{2}{*}{ OAs } & \multirow{2}{*}{ Rate $\mathrm{g} / \mathrm{kg}$ soil } & \multicolumn{2}{|c|}{$\mathrm{SH}(\mathrm{cm})$} & \multicolumn{2}{|c|}{ FSW (gm) } & \multicolumn{2}{|c|}{ FRW (gm) } & \multirow{2}{*}{$\begin{array}{c}\mathrm{J} 2 / 200 \mathrm{cc} \text { soil } \\
+\mathrm{N}\end{array}$} & \multirow{2}{*}{$\begin{array}{l}\mathrm{GI}^{*} \\
+\mathrm{N}\end{array}$} & \multirow{2}{*}{$\begin{array}{l}\mathrm{Rf} \\
+\mathrm{N}\end{array}$} \\
\hline & & $+\mathrm{N}$ & $-\mathrm{N}$ & $+\mathrm{N}$ & $-\mathrm{N}$ & $+\mathrm{N}$ & $-\mathrm{N}$ & & & \\
\hline \multirow{3}{*}{ TD } & 2.5 & $14.0 \mathrm{~d}$ & $28.6 \mathrm{ab}$ & $2.2 \mathrm{~cd}$ & $2.4 \mathrm{~cd}$ & $0.15 \mathrm{~cd}$ & $0.64 \mathrm{bc}$ & $22.5 \mathrm{a}$ & $3.3 \mathrm{~b}$ & $3.6 \mathrm{bc}$ \\
\hline & 5 & $23.1 \mathrm{~b}$ & $30.8 \mathrm{a}$ & $2.5 \mathrm{~cd}$ & $3.5 c$ & $0.28 \mathrm{c}$ & $1.28 \mathrm{ab}$ & $14.0 \mathrm{ab}$ & $3.0 \mathrm{~b}$ & $2.9 \mathrm{bc}$ \\
\hline & 8 & $24.8 \mathrm{bc}$ & $32.4 \mathrm{a}$ & $2.8 \mathrm{~cd}$ & $3.8 \mathrm{c}$ & $0.33 c$ & $1.79 \mathrm{ab}$ & $11.3 \mathrm{ab}$ & $1.0 \mathrm{~cd}$ & $0.7 \mathrm{c}$ \\
\hline \multirow{3}{*}{ PM } & 3 & $14.9 \mathrm{~cd}$ & $28.3 \mathrm{ab}$ & $2.1 \mathrm{~cd}$ & $3.7 \mathrm{c}$ & $0.56 \mathrm{bc}$ & $1.09 \mathrm{~b}$ & $4.3 \mathrm{~b}$ & $3.3 b$ & $4.7 \mathrm{~b}$ \\
\hline & 6 & $24.7 \mathrm{~b}$ & $30.83 a$ & $4.0 \mathrm{c}$ & $3.9 \mathrm{c}$ & $0.57 \mathrm{bc}$ & $1.84 \mathrm{~b}$ & $2.5 \mathrm{c}$ & $3.3 \mathrm{~b}$ & $3.7 \mathrm{bc}$ \\
\hline & 9 & $20.8 c$ & $31.2 \mathrm{a}$ & $3.8 \mathrm{c}$ & $5.0 \mathrm{bc}$ & $0.59 \mathrm{bc}$ & $2.61 \mathrm{a}$ & $1.8 \mathrm{~cd}$ & $1.5 \mathrm{c}$ & $0.98 \mathrm{c}$ \\
\hline \multirow{3}{*}{ Tres } & 14 & $28.3 \mathrm{ab}$ & $26.0 \mathrm{ab}$ & $6.4 \mathrm{~b}$ & 7.9ab & $0.6 \mathrm{bc}$ & $1.1 \mathrm{~b}$ & $2.5 \mathrm{c}$ & $3.3 \mathrm{~b}$ & $3.0 \mathrm{bc}$ \\
\hline & 28 & $29.9 \mathrm{ab}$ & $27.7 \mathrm{ab}$ & $8.5 \mathrm{a}$ & $7.88 \mathrm{ab}$ & $0.57 \mathrm{bc}$ & $2.6 \mathrm{a}$ & $3.0 \mathrm{c}$ & $1.5 \mathrm{c}$ & $0.7 \mathrm{c}$ \\
\hline & 32 & $23.1 \mathrm{~b}$ & $23.7 \mathrm{~b}$ & $6.7 \mathrm{ab}$ & $6.9 \mathrm{ab}$ & $0.3 \mathrm{~cd}$ & $1.8 \mathrm{ab}$ & $1.0 \mathrm{~cd}$ & $1.0 \mathrm{~cd}$ & $0.3 \mathrm{c}$ \\
\hline \multirow{3}{*}{$\mathrm{CM}$} & 3 & $17.5 \mathrm{~cd}$ & $24.3 \mathrm{~b}$ & $0.2 \mathrm{de}$ & $0.9 \mathrm{~d}$ & $0.26 c$ & $0.7 \mathrm{bc}$ & $20.8 \mathrm{a}$ & $3.0 \mathrm{~b}$ & $3.7 \mathrm{bc}$ \\
\hline & 6 & $22.3 b c$ & $26.1 \mathrm{ab}$ & $0.3 \mathrm{de}$ & $1.1 \mathrm{~d}$ & $0.25 c$ & $0.44 c d$ & $9.3 b$ & $1.8 \mathrm{c}$ & $1.3 \mathrm{c}$ \\
\hline & 9 & $25.9 b$ & $28.3 \mathrm{ab}$ & 0.6 de & $3.7 \mathrm{c}$ & $0.32 c$ & $0.55 b c$ & $4.3 \mathrm{bc}$ & $1.5 \mathrm{c}$ & $0.9 \mathrm{c}$ \\
\hline \multirow{3}{*}{ VWR (\%) } & 20 & $12.7 \mathrm{~d}$ & $16.8 \mathrm{~cd}$ & $1.5 \mathrm{~d}$ & $2.5 \mathrm{~cd}$ & $1.0 \mathrm{~b}$ & $1.86 \mathrm{ab}$ & $8.0 \mathrm{ab}$ & $3.0 \mathrm{~b}$ & $2.2 \mathrm{bc}$ \\
\hline & 60 & $12.2 \mathrm{~d}$ & $12.4 \mathrm{~d}$ & $1.9 \mathrm{~cd}$ & $1.1 \mathrm{~d}$ & $0.78 \mathrm{c}$ & $0.7 \mathrm{c}$ & $4.0 \mathrm{bc}$ & $2.5 \mathrm{bc}$ & $2.6 \mathrm{bc}$ \\
\hline & 100 & $9.4 \mathrm{de}$ & $10.8 \mathrm{~d}$ & $1.5 \mathrm{~d}$ & $0.6 \mathrm{de}$ & $0.71 \mathrm{c}$ & $0.9 \mathrm{c}$ & $2.3 \mathrm{c}$ & $1.5 \mathrm{c}$ & $1.2 \mathrm{c}$ \\
\hline Unamended control & - & $10.5 \mathrm{~d}$ & $15.9 \mathrm{~cd}$ & $2.4 \mathrm{~cd}$ & $3.3 c$ & $0.29 c$ & $0.87 c$ & $24.8 \mathrm{a}$ & $4.8 \mathrm{a}$ & $14.7 \mathrm{a}$ \\
\hline$P$ value & 一 & 0.000 & 0.000 & 0.000 & 0.000 & 0.000 & 0.000 & 0.000 & 0.000 & 0.000 \\
\hline
\end{tabular}

Means followed by the same letter within each column are not significantly different $(P>0.05)$ as indicated by Fisher's LSD test.

${ }^{*}$ Gall index on a $0-5$ gall rating scale according to Quesenberry et al. [17] where $0=$ no galls, $1=1-2,2=3-10,3=11-30,4=31-100$, and $5 \geq 100$ galls per root system.

the effect of these materials as well as a myriad of factors that may have converted the toxic tannins and phenolic compounds into soluble and utilizable form by plants. The findings by Nico et al. [22] using decomposed agro-industrial waste of dry cork, grape marc, olive marc, and rice husk as soil amendments for the management of Meloidogyne spp. reported tremendous suppression of RKN and promoted plant growth.

The results revealed that TD, PM, Tres, and CM performed best in improving plant growth although VWR and Tres were the best in suppression of RKN reproduction, galling and $\mathrm{J} 2$ populations. Improved plant growth recorded in plants grown on TD, PM and Tres may be attributed to higher nitrogen content and narrow $\mathrm{C} / \mathrm{N}$ ratio in these materials as reported in Table 2, compared to CM and GM. Higher nitrogen content and narrow $\mathrm{C} / \mathrm{N}$ ratio are associated with control of nematodes in amended soils.

\section{Conclusion and Recommendation}

Root-knot nematode is among the greatest threats to vegetable production in Kenya. The results revealed suppression of RKN population and reproduction by the various amendments compared to their controls in both field and greenhouse tests. Improved plant growth was also recorded in all the amendments in both tests except for Tres and VWR at higher rates of application.

This study has therefore revealed that amending soils with organic materials and agro-industrial wastes are beneficial for the management of RKN on black nightshades. These organic amendments are common, abundant, cheap, and readily available in the rural areas of Kisii and Kilgoris counties of Kenya. The agro-industrial wastes, Tithonia diversifolia, cattle, and goat manure have potential in the management of RKN on S. nigrum. Nematode GI, Rf, and 
TABLE 6: Comparative efficacy of agro-industrial wastes and OAs on RKN on SG in field test.

\begin{tabular}{|c|c|c|c|c|c|}
\hline \multirow{3}{*}{ Amendment } & \multicolumn{5}{|c|}{ Efficacy of amendments on GI, J2 and Rf of RKN } \\
\hline & \multicolumn{2}{|c|}{ J2/200 cc soil } & \multicolumn{2}{|c|}{ GI } & \multirow{2}{*}{$\begin{array}{c}\mathrm{Rf} \\
-\mathrm{M}\end{array}$} \\
\hline & $-\mathrm{M}$ & $+\mathrm{M}$ & $-\mathrm{M}$ & $+\mathrm{M}$ & \\
\hline TD & $19.8 \mathrm{~d}$ & $16.0 \mathrm{~d}$ & $2.0 \mathrm{ab}$ & $1.3 \mathrm{ab}$ & $0.88 \mathrm{bc}$ \\
\hline Tres & $33.8 \mathrm{~cd}$ & $9.0 \mathrm{~d}$ & $1.5 \mathrm{ab}$ & $1.0 \mathrm{ab}$ & $0.49 \mathrm{bc}$ \\
\hline $\mathrm{CM}$ & $75.0 \mathrm{~b}$ & $5.0 \mathrm{~d}$ & $2.0 \mathrm{ab}$ & $0.8 \mathrm{~b}$ & $0.3 \mathrm{bc}$ \\
\hline Trej & $45.8 \mathrm{bc}$ & $5.5 \mathrm{~d}$ & $2.3 \mathrm{a}$ & $1.3 \mathrm{ab}$ & $0.47 \mathrm{bc}$ \\
\hline GM & $78.0 \mathrm{~b}$ & $10.8 \mathrm{~d}$ & $2.5 \mathrm{a}$ & $1.5 \mathrm{a}$ & $0.35 \mathrm{bc}$ \\
\hline Unamended & $119.5 \mathrm{a}$ & $40.0 \mathrm{c}$ & $3.3 \mathrm{a}$ & $1.3 \mathrm{ab}$ & $15.0 \mathrm{a}$ \\
\hline$P$ value & 0.000 & 0.000 & 0.077 & 0.018 & 0.000 \\
\hline
\end{tabular}

Means on the same column followed by similar letter $(s)$ are not significantly different $(P>0.05)$.

J2 population were suppressed by agro-industrial wastes, $\mathrm{TD}, \mathrm{CM}$, and GM. Increased plant growth in amended plants confirms potential of the agro-industrial and organic amendments into improved plant growth. These materials therefore provide a new nonchemical alternative strategy for the management of RKN and other phytonematodes on $S$. nigrum by the poor-resource farmers with minimal effects on the environment. Due to stunting at higher levels of application in tea residue and VWR, lower rates of $28 \mathrm{~g} / \mathrm{kg}$ soil and $20 \%$ for Tres and VWR, respectively, are recommended. Further studies are therefore necessary for identification of the active components and contribution of these materials in affecting the population of antagonistic organisms for controlling nematodes in the wake of reducing dependence on chemical nematicides.

\section{Acronyms/Abbreviations}

RKN: Root-knot nematodes

Trej: Tea rejects

Tres: Tea residue

TD: Tithonia diversifolia

PM: Pyrethrum marc

CM: Cattle manure

VWR: Vegetable waxy resins

SG: Solanum nigrum green-berried variety

OA: Organic amendment

M: Mocap

GI: $\quad$ Galling index

J2: $\quad$ Second stage juveniles

Rf: Reproduction factor

SH: Shoot height

FRW: Fresh root weight

FSW: Fresh shoot weight.

\section{References}

[1] J. A. Chweya and P. B. Eyzaguirre, The Biodiversity of Traditional Leafy Vegetables, International Plant Genetic Resources Institute, Rome, Italy, 1999.

[2] P. M. Maundu, G. W. Ngugi, and C. H. Kabuye, Traditional Food Plants of Kenya, KENRIK, National Museums of Kenya, 1999.
[3] Government of Kenya, National Home-Based Care Programme and Service Guidelines. National AIDS, STD Control Programme, Ministry of Health, 2002.

[4] J. O. Kokwaro, Medicinal Plants of East Africa, East African Literature Bureau, Nairobi, Kenya, 1976.

[5] J. M. Edmonds and J. A. Chweya, Black Nightshades (Solanum Nigrum L.) and Related Species. Promoting Conservation and Use of Underutilized and Neglected Crops, International Plant Genetic Resources Institute, Rome, Italy, 1997.

[6] B. S. Rogers and A. G. Ogg, "Biology of weeds of the Solanum nigrum complex (Solanum section Solanum) in North America," in United States Deptartment of Agriculture, Science and Education Administration, pp. 1-30, Agricultural Reviews and Manuals, Western Series No. 23, 1981.

[7] G. R. Stirling, J. M. Stanton, and J. W. Marshall, "The importance of plant parasitic nematodes to Australian and New Zealand agriculture," Australian Plant Pathology, vol. 21, pp. 104-115, 1992.

[8] I. A. Udo and K. I. Ugwuoke, "Pathogenicity of Meloidogyne incognita race 1 on turmeric (Curcuma longa L.) as influenced by inoculum density and poultry manure amendment," Plant Pathology Journal, vol. 9, no. 4, pp. 162-168, 2010.

[9] A. Piedra-Buena, A. García-Álvarez, M. Á. Díez-Rojo, and A. Bello, "Use of crop residues for the control of Meloidogyne incognita under laboratory conditions," Pest Management Science, vol. 62, no. 10, pp. 919-926, 2006.

[10] J. W. Waceke, "Role of organic soil amendments in the management of root-knot nematodes on Okra," in Proceedings of the Horticulture Seminar on Sustainable Horticultural Production in the Tropics, J. M. Wesonga, T. Losenge, C. K. Ndung'u et al., Eds., pp. 113-117, JKUAT, Juja, Kenya, 2001.

[11] J. W. Waceke, "Organic soil amendments: an integrated approach to root- knot nematode management on okra," in Proceedings of the Integrated Pest Management conference for sub-Saharan Africa, pp. 8-12, Kampala, Uganda, September 2002.

[12] L. Rivera and E. Aballay, "Nematicide effect of various organic soil amendments on Meloidogyne ethiopica whitehead, 1968, on potted vine plants," Chilean Journal of Agricultural Research, vol. 68, no. 3, pp. 290-296, 2008.

[13] B. Jama, C. A. Palm, R. J. Buresh et al., "Tithonia diversifolia as a green manure for soil fertility improvement in western Kenya: a review," Agroforestry Systems, vol. 49, no. 2, pp. 201221, 2000.

[14] J. W. Kimenju, A. M. Kagundu, J. H. Nderitu, F. Mambala, G. K. Mutua, and G. M. Kariuki, "Incorporation of green manure plants into bean cropping systems contribute to root-knot 
nematode suppression," Asian Journal of Plant Sciences, vol. 7, no. 4, pp. 404-408, 2008.

[15] M. Abukutsa-Onyango, "The diversity of cultivated African leafy vegetables in three communities in Western Kenya," African Journal of Food, Agriculture, Nutrition and Development, vol. 7, no. 3, 2007.

[16] A. S. Hasabo and E. M. A. Noweer, "Management of root-knot nematode Meloidogyne incognita on eggplant with some plant extracts," Egyptian Journal of Phytopathology, vol. 33, no. 2, pp. 65-72, 2005.

[17] K. H. Quesenberry, D. D. Baltensperger, R. A. Dunn, C. J. Wilcox, and S. R. Hardy, "Selection for tolerance to root-knot nematodes in red clover," Crop Science, vol. 29, pp. 62-66, 1989.

[18] D. J. Hooper, J. Hallmann, and S. Subbotin, "Methods for extraction, processing and detection of plant and soil nematodes," in Plant Parasitic Nematodes in Subtropical and Tropical Agriculture, M. Luc, R. A. Sikora, and Bridge, Eds., pp. 53-86, CAB International, Wallingford, UK, 2nd edition, 2005.

[19] F. Zhang and D. P. Schmitt, "Host status of 32 plant species to Meloidogyne konaensis," Journal of Nematology, vol. 26, no. 4, pp. 744-748, 1994.

[20] D. M. Huber, "The use of fertilizers and or amendments in the control of plant diseases," Handbook of Pest Management and Agriculture, vol. 1, pp. 357-393, 1980.

[21] Y. Oka, "Mechanisms of nematode suppression by organic soil amendments-A review," Applied Soil Ecology, vol. 44, no. 2, pp. 101-115, 2010.

[22] A. I. Nico, R. M. Jiménez-Díaz, and P. Castillo, "Control of root-knot nematodes by composted agro-industrial wastes in potting mixtures," Crop Protection, vol. 23, no. 7, pp. 581-587, 2004. 


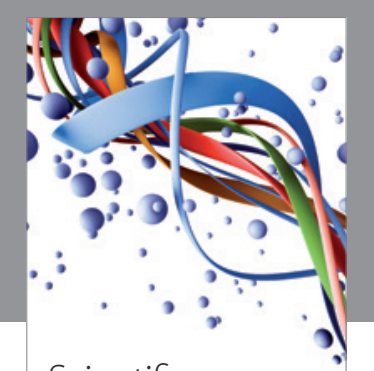

Scientifica
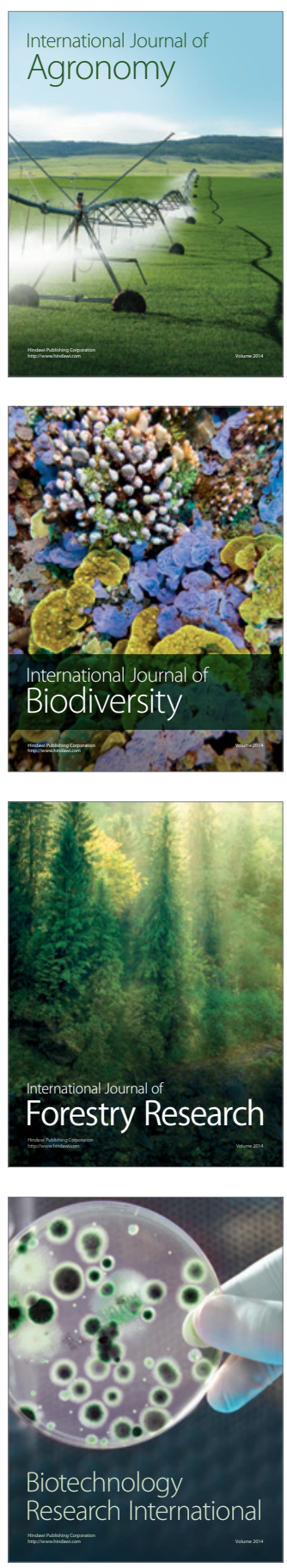
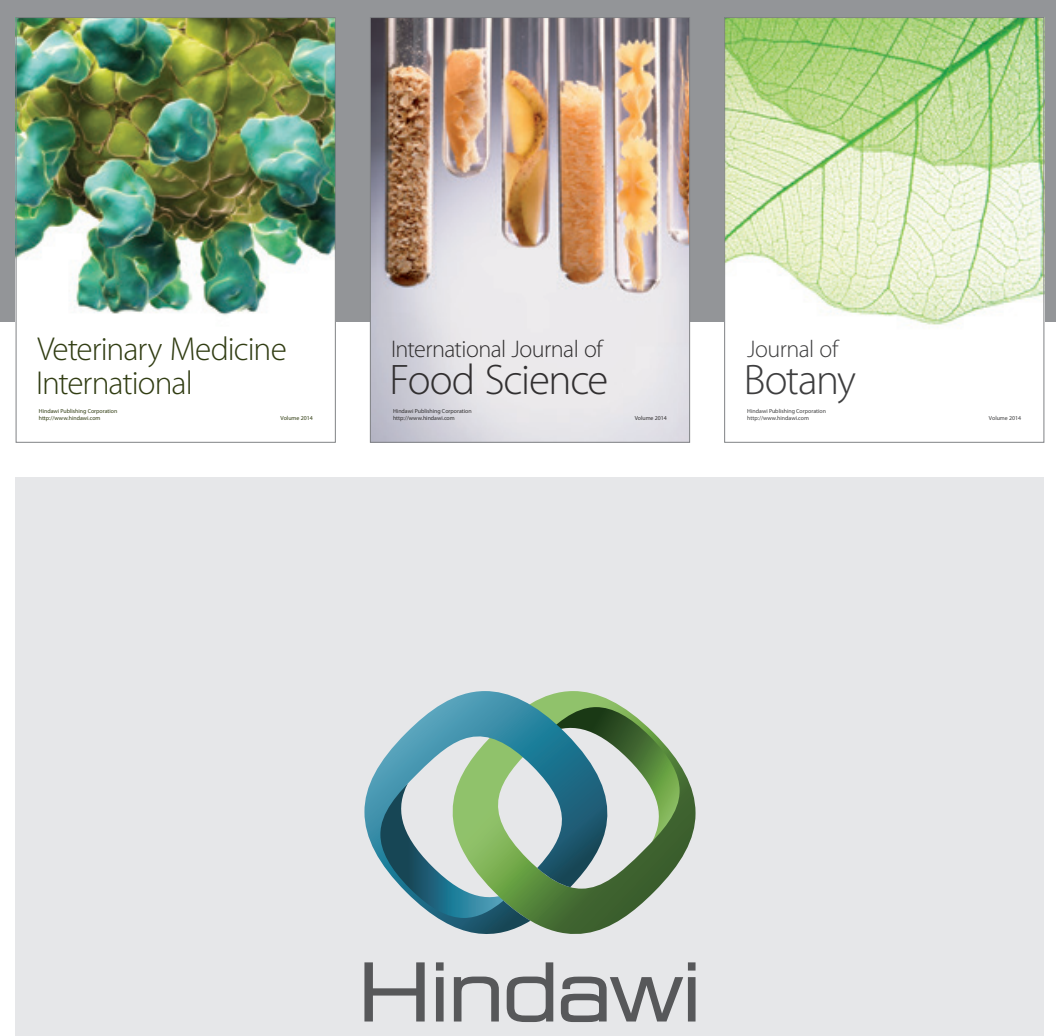

Submit your manuscripts at

http://www.hindawi.com
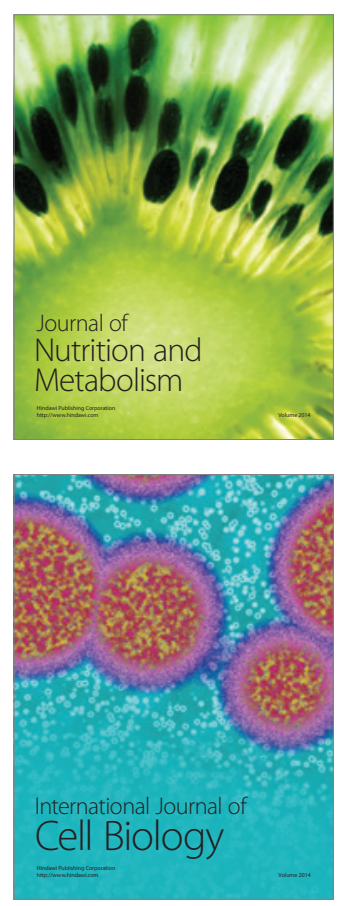
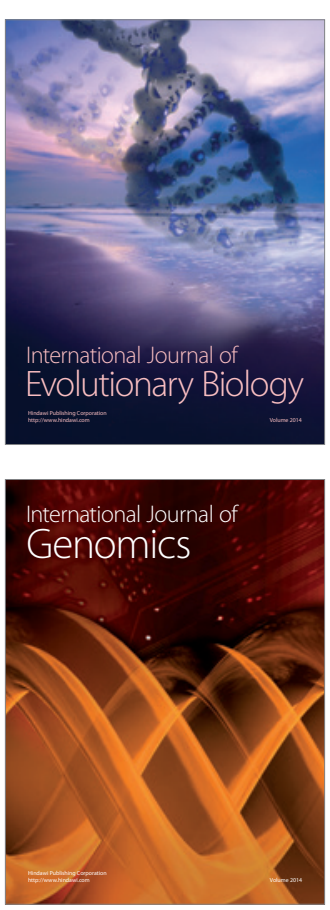
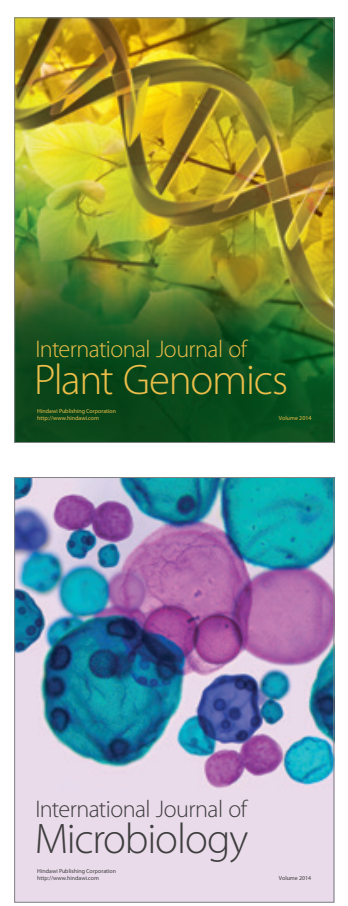

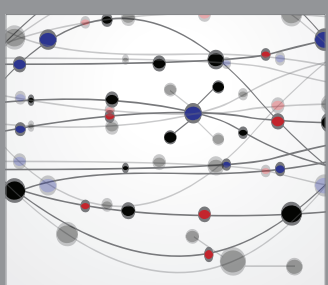

The Scientific World Journal
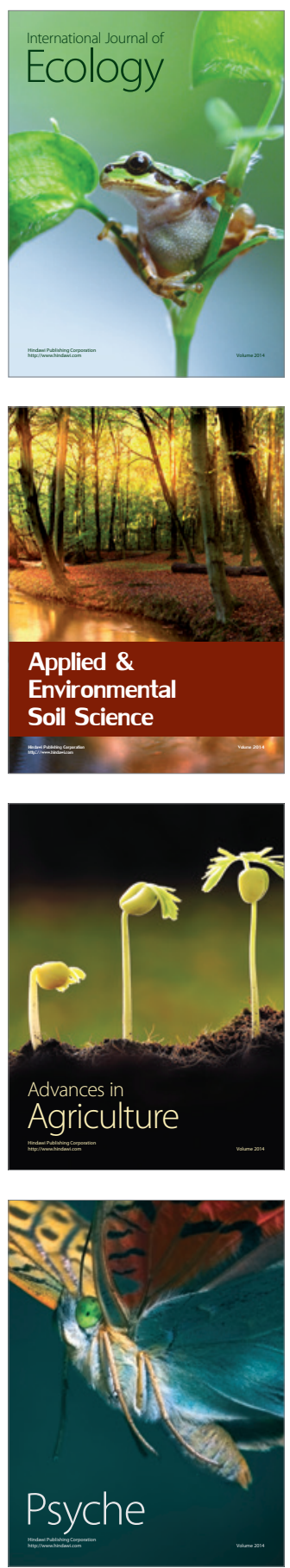